\title{
Biologic Width: Evaluation and Correction of its Violation
}

\author{
Nitin Khuller, Nikhil Sharma
}

\section{ABSTRACT}

The concept of Biologic Width has been widely described by periodontists and restorative dentists. An adequate understanding of relationship between periodontal tissues and restorative dentistry is paramount to ensure adequate form, function and esthetics, and comfort of the dentition. While most clinicians are aware of this important relationship, uncertainty remains regarding specific concepts such as biologic width and indications and applications of surgical crown lengthening. These violations lead to complications like gingival inflammation, alveolar bone loss and improper fit of the restorative component. An attempt has been made in this article to discuss the concept of biologic width, its importance in maintaining a long term dental restoration including crown \& bridge and implants, and the implications of biologic width violation. Lastly, we discuss the possible methods to assess biologic width and surgical \& non-surgical corrective procedures.

\section{Contact Author}

Dr Nikhil Sharma

E mail: nkhuller@yahoo.com

Key Words: Biologic, width, Dentogingival unit, Periodontics, restorations, Gingival inflammation, Bone loss, Crown lengthening.

$\mathrm{T}$ The biological width is defined as the dimension of the soft tissue, which is attached to the portion of the tooth coronal to the crest of the alveolar bone. This term was based on the work of Gargiulo et al (1961), who described the dimensions and relationship of the dentogingival junction in humans.(1) Measurements made from the dentogingival components of 287 individual teeth from 30 autopsy specimens established that there is a definite proportional relationship between the alveolar crest, the connective tissue attachment, the epithelial attachment, and the sulcus depth. They reported the following mean dimensions: a sulcus depth of $0.69 \mathrm{~mm}$, an epithelial attachment of $0.97 \mathrm{~mm}$, and a connective tissue attachment of $1.07 \mathrm{~mm}$. (Fig. 1) Based on this work, the biologic width is commonly stated to be $2.04 \mathrm{~mm}$, which represents the sum of the epithelial and connective tissue measurements. One must realize however that significant variations of dimensions were observed, particularly the epithelial attachment, which ranged from 1.0 to $9.0 \mathrm{~mm}$. The connective tissue attachment, on the other hand, was relatively constant. Similar biologic width dimensions were also reported by Vacek et al 1994.(2) Evaluating 171 cadaver tooth surfaces, they observed mean measurements of $1.34 \mathrm{~mm}$ for sulcus depth,
1.14 for epithelial attachment, and $0.77 \mathrm{~mm}$ for connective tissue attachment. This group also found that the connective tissue attachment was the most consistent measurement.

\section{Concept of biologic width}

There is general agreement that placing restorative margins within the biologic width frequently leads to gingival

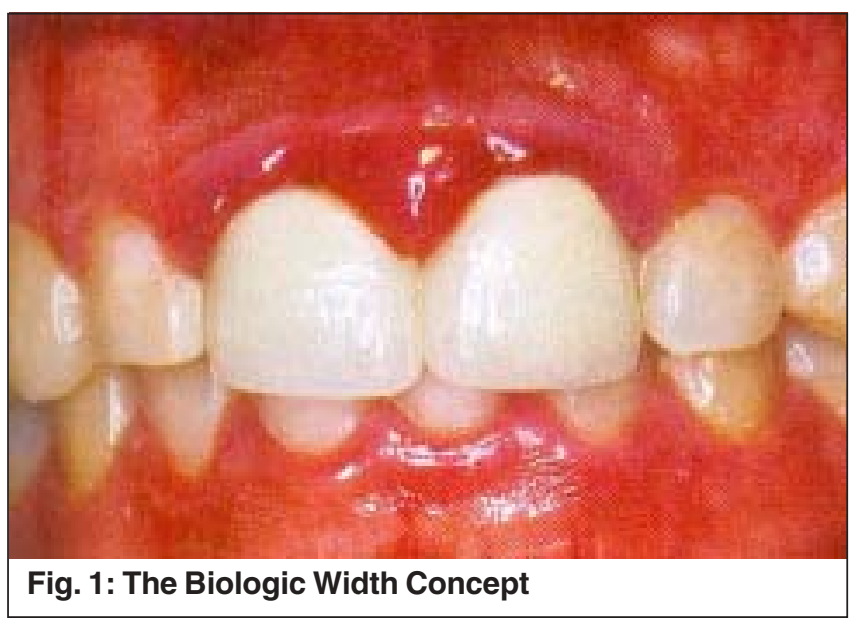


inflammation, clinical attachment loss, and bone loss. This is thought to be due to the destructive inflammatory response to microbial plaque located at deeply periodontal pockets or gingival recession. These changes have been substantiated be studies that have assessed the histological and clinical responses of periodontal tissues to restorative margins placed within the biologic width. Newcomb (1974) analyzed 66 anterior crowns with subgingival margins of varying depths and compared them to uncrowned contra lateral controls.(3) The results showed that the nearer a subgingival crown margin was to the epithelial attachment (hence nearer the biologic width), the more likely that severe gingival inflammation occurred. Parma-Benfenati et al (1986) observed approximately $5 \mathrm{~mm}$ of osseous resorption when restorative margins were placed at the alveolar crest in beagle dogs.(4) Minimal resorption was observed where restorations were placed $4 \mathrm{~mm}$ coronal to the alveolar crest. Tal et al. (1989) further demonstrated that biological width violation results in loss of periodontal support.(5) Class V cavities were prepared in canine teeth of 43 beagle dogs so that the apical border rested on the alveolar crest. Control teeth had Class V notches placed at the cemento-enamel junction. All cavities were restored with amalgam, and 1 year following surgery, gingival recession and bone loss were significant greater at test sites compared to control teeth $(3.16$ and $1.17 \mathrm{~mm}$ versus 0.5 and $0.15 \mathrm{~mm}$, respectively). Similarly, Gunay et al (2000) demonstrated that restorative margin placement within the biologic width was detrimental to periodontal health.(6) In a 2-year study, they evaluated 116 prepared teeth compared to 82 unrestored teeth in 41 patients and found that the papillary bleeding score and probing depths increased at sites where the restorative margin was $<1 \mathrm{~mm}$ from the alveolar crest.

Encroachment of the biologic width becomes of particular concern when considering the restoration of a tooth that has fractured or been caries near the alveolar crest. Also, esthetic demands often require "burying" of restorative margins subgingivally, which can lead to violation of this space. Various authors have recommended minimal distances restorative margins must be from the bone crest to avoid deleterious effects. Ingber et al (1977) suggested that a minimum of $3 \mathrm{~mm}$ was required from the restorative margin to the alveolar crest to permit adequate healing and restoration of the tooth.(7)

Maynard \& Wilson (1979) divided the periodontium into three dimensions; superficial physiologic, crevicular physiologic and subcrevicular physiologic.(8) The superficial physiologic dimension represents the free and attached gingival surrounding the tooth, while the crevicular physiologic dimension represents the gingival dimension from the gingival margin to the junctional epithelium. The subcrevicular physiologic space is analogous to the biologic width described (Gargiulo et al. 1961), consisting of the junctional epithelium and connective tissue attachnment.(1) Maynard \& Wilson claimed that all three of these dimensions affect restorative treatment decisions and the clinician should 'conceptualize' all three areas and the interplay between them and restorative margins.(8) In particular, the authors claimed that margin placement into the subcrevicular physiologic space should be avoided to prevent the placement of 'permanent calculus' beyond the crevice.

Nevins \& Skurow (1984) stated that when subgingival margins are indicated, the restorative dentist must not disrupt the junctional epithelium or connective tissue apparatus during preparation and impressing taking.(9) The authors recommended limiting subgingival margin extension to $0.5-1.0$ $\mathrm{mm}$ because it is impossible for the clinician to detect where the sulcular epithelium ends and the sulcular epithelium ends and the junctional epithelium begins. They also emphasized allowing a minimum $3.0 \mathrm{~mm}$ distance from the alveolar crest to the crown margin.

\section{Biological width concept and dental implants}

The implant-epithelium junction is similar to that in the natural dentition, except that it is shorter and thinner than the toothepithelium junction. Because of the absence of a cementum layer around an implant, most connective-tissue fibers in supracrestal region are oriented in a direction parallel to the implant surface. Furthermore, investigators have observed the presence of an avascular zone, 50 to 100 micrometers wide, of dense circular connective-tissue fibers that are in direct contact with the implant post at the supracrestal area. The biological width around implants can have significant influence on the character of soft tissues and depends on a variety of characteristics that include implant design, presence of adjacent teeth and quality of soft tissue. For example, onepiece implant designs have been implicated in more closely mimicking the biological width around natural teeth. Similarly, platform switching (as in controlling the dimension of the abutment) during the period of osseointegration affects biological width by altering the position of the microgap and controlling circumferential bone loss around dental implants. In addition, a scalloped implant platform is available that follows the osseous structure of the maxillary anterior teeth and may prevent interproximal crestal bone resorption during healing. These results may have important implications when dealing with esthetic implant-borne restorations, considering that longterm esthetic survival depends on soft-tissue dimensions that remain healthy and vertically constant over time.(10)

\section{Evaluation of biologic width}

Radiographic interpretation can identify interproximal violations of biologic width. However, with the more common locations on the mesiofacial and distofacial line angles of teeth, radiographs are not diagnostic because of tooth superimposition. If a patient 
experiences tissue discomfort when the restoration margin levels are being assessed with a periodontal probe, it is a good indication that the margin extends into the attachment and that a biologic width violation has occurred.

The biologic, or attachment, width can be identified for each individual patient by probing under anesthesia to the bone level (referred to as "sounding to bone") and subtracting the sulcus depth from the resulting measurement. This measurement must be performed on teeth with healthy gingival tissues and should be repeated on more than one tooth to ensure an accurate assessment. The technique allows the variations in sulcus depths found in individual patients to be assessed and factored into the diagnostic evaluation. The information obtained is then used to definitively diagnose biologic width violations, the extent of correction needed, and the parameters for placement of future restorations.

\section{Restorative margin location Margin placement and biologic width}

A clinician is presented with three options for margin placement: supragingival, equigingival (even with the tissue), and subgingival locations. The supragingival margin has the least impact on the periodontium. Classically, this margin location has been applied in non-esthetic areas due to the marked contrast in color and opacity of traditional restorative materials against the tooth. With the advent of more translucent restorative materials, adhesive dentistry, and resin cements, the ability to place supragingival margins in esthetic areas is now a reality. Therefore whenever possible, these restorations should be chosen not just for their esthetic advantage but for their favorable periodontal impact as well.

The use of equigingival margins traditionally was not desirable because they were thought to train more plaque than supragingival or subgingival margins and therefore result in greater gingival inflammation. There was also the concern that any minor gingival recession would create an unsightly margin display. These concerns are not valid today, not only because the restoration margins can be esthetically blended with the tooth but also because restorations can be finished easily to provide a smooth, polished interface at the gingival margin. From a periodontal viewpoint, both supragingival and equigingival margins are well tolerated. The greatest biologic risk occurs when placing subgingival or equigingival margins for finishing procedures, and in addition, if the margin is placed too far below the gingival tissue crest, it violates the gingival attachment apparatus.

When the restoration margin is placed too far below the gingival tissue crest, it impinges on the gingival attachment apparatus and creates a violation of biologic width. (Fig. 2) Two different responses can be observed from the involved gingival tissues.
One possibility is that bone loss of an unpredictable nature and gingival tissue recession occur as the body attempts to recreate room between the alveolar bone and the margin to allow space for tissue reattachment. This is more likely to occur in areas where the alveolar bone surrounding the tooth is very thin. Trauma from restorative procedures can play a major role in causing this fragile tissue to recede.

The first step in using sulcus depth as a guide in margins placement is to manage gingival health. Once the tissue is healthy, the following three rules can be used to place intracrevicular margins.(11)

- If the sulcus probes $1.5 \mathrm{~mm}$ or less, place the restoration margin $0.5 \mathrm{~mm}$ below the gingival tissue crest. This is especially important on the facial aspect and prevents a biologic width violation in a patient who is at high risk in that regard.

- If the sulcus probes more than $1.5 \mathrm{~mm}$, place the margin one half the depth of the sulcus below the tissue crest. This places the margin far enough below tissue so that it still is covered if the patient is at higher risk of recession.

- If a sulcus greater than $2 \mathrm{~mm}$ is found, especially on the facial aspect of the tooth, then evaluate to see whether a gingivectomy could be performed to lengthen the teeth and create a $1.5 \mathrm{~mm}$ sulcus. Then the patient can be treated using Rule 1.

Orkin et al. (1987) demonstrated that subgingival restorations had a greater chance of bleeding and exhibiting gingival recession than supragingival restorations.(12) Waerhaug (1978) stated that subgingival restorations are plaque-retentive areas that are inaccessible to scaling instrument.(13) These retentive areas continue to accumulate plaque even in the

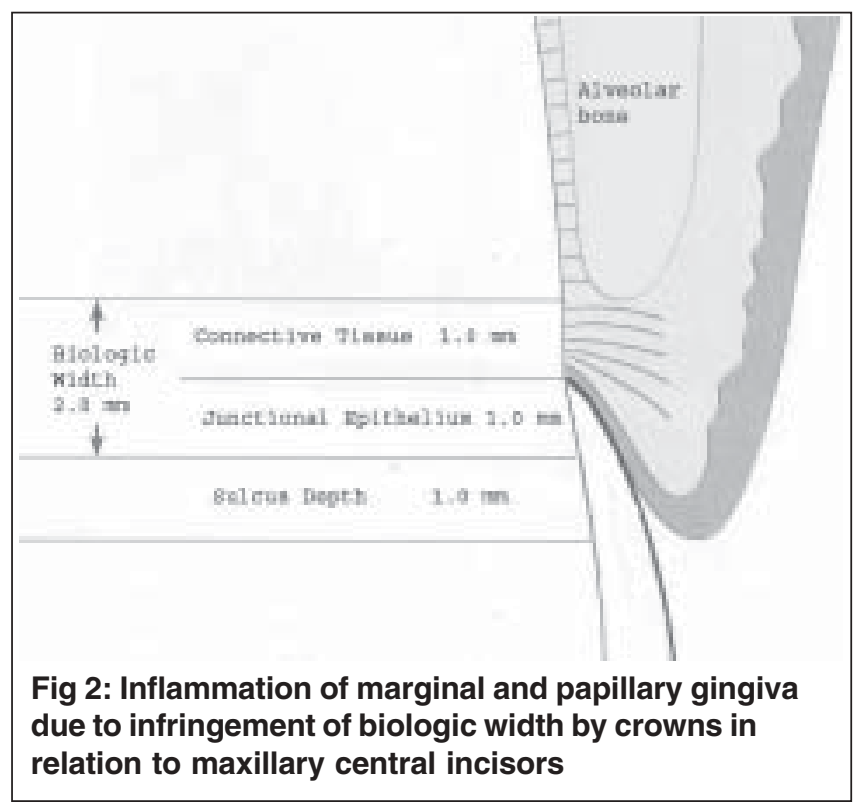


presence of adequate supragingival plaque control. Stetler \& Bissada (1987) evaluated the effects of width of keratinized gingival and subgingival restorations on periodontal health.(14) Teeth with subgingival restorations and narrow zones of keratinized gingival showed significantly higher gingival index scores than teeth with sub marginal restorations with wide zones of keratinized gingival. Thus clinicians should consider gingival augmentation for teeth with minimal keratinized gingiva before placing subgingival restorations.

Waerhaug (1980) demonstrated gingivitis and attachment loss associated with sub marginal restorations in monkeys and dogs.(15) Clinical and histological observations of human teeth by Dragoo \& Williams (1981) demonstrated compromised healing associated with gingival bevel crown margins compared to shoulder preparations.(16) Flores-de-je-Coby et al (1989) studied the effects of crowns margin location on periodontal heath and bacterial morphotypes in humans 6-8 weeks and 1 year post insertion.(17) Subgingival margins demonstrated increased plaque, gingival index scores, and probing depths. Further more, more spirochetes, fusiforms, rods, and filamentous bacteria were found to be associated with subgingival margins. Valderhaug \& Birkeland (1976) evaluated 114 patients with 329 total crown restorations.(18) Most of the crowns (59\%) were located subgingivally at the beginning of the study period. After 5 years, only $32 \%$ of the crown margins remained below the gingival margin. They also demonstrated compared to supragingival margins (1.2 versus $0.6 \mathrm{~mm})$.

\section{Correction of biologic width violations}

Biologic width violations can be corrected by either surgically removing bone away from proximity to the restoration margin or orthodontically extruding the tooth and thus moving the margin away from the bone. Surgery is the more rapid of the two treatment options. It is also preferred if the resulting crown lengthening will create a more pleasing tooth length. In these situations, the bone should be moved away from the margin by the measured distance of the ideal biologic width for that patient, with an additional $0.5 \mathrm{~mm}$ of bone removed as a safety zone.

Gingival recession is a potential risk after removal of bone. If interproximal bone is removed, there is a high likelihood of papillary recession and the creation of an unaesthetic triangle of space below the interproximal contacts. If the biologic width violation is on the interproximal, or if the violation is across the facial surface and the gingival tissue level is correct, then orthodontic extrusion is indicated. The extrusion can be performed in two ways. By applying low orthodontic extrusion force, the tooth is erupted slowly, bringing the alveolar bone and gingival tissue with it. The tooth is extruded until the bone level has been carried coronal to the ideal level by the amount that needs to be removed surgically to correct the attachment violation. The tooth is stabilized in this new position and then treated with surgery to correct the bone and gingival tissue levels. Another option is to carry out rapid orthodontic extrusion whereby the tooth is erupted the desired amount over several weeks. During this period, a supracrestal fibrotomy is performed weekly in an effort to prevent the tissue and bone from following the tooth. The tooth is then stabilized for at least 12 weeks to confirm the position of the tissue and bone, and any coronal creep can be corrected surgically.

\section{Surgical crown lengthening}

Crown -lengthening surgery is designed to increase clinical crown length for various reasons. The clinical crown is that portion of the tooth that extends occlusally or incisally from the investing soft tissue, usually the gingiva (American Academy of Periodontology 1992).(11) Teeth with subgingival caries, fractures, short clinical crowns with or without esthetic deficiencies, and teeth shortened by incomplete exposure of the anatomic crown are all candidates for surgical lengthening. While many situations require it, crown-lengthening surgery is often underutilized. Because of this, too much reliability is placed on post and core restorations and deep subgingival margin placement to gain adequate retention for restorative purposes. This often leads to root fractures, in the case of post and core restorations, and violation of the biologic with in the case of deep subgingival margins. These factors contribute to greater expense and frustration fir the patient, hence further complicating restorative and periodontal therapy.

\section{Crown lengthening procedures}

To select the proper treatment approach for crown lengthening, an analysis of the individual case with regard to crown-rootalveolar bone relationships should also be included.

If a patient complains about their "small front teeth" and the periodontium is of a thin biotype, full exposure of the anatomical crown can be accomplished by a gingivoplasty/gingivectomy (external bevel or internal bevel) procedure.

\section{External bevel gingivectomy}

When there is more than adequate attached gingiva and no bone involvement, one method of eliminating excessive packet depth and or of exposing additional coronal tooth structure is by external-bevel gingivectomy.

\section{Internal bevel gingivectomy}

Reduction of excessive pocket depth and exposure of additional coronal tooth structure in the absence of a sufficient zone of attached gingiva with or without the need for correction of osseous abnormalities requires a different surgical procedure. In such cases, the external-bevel gingivectomy would remove all or most of the attached gingival, leaving nothing but alveolar 
mucosa. If correction of osseous pathology is needed, the flap must always be internally beveled so as to expose the supporting alveolar bone.

\section{Apically positioned flap with bone recontouring} The apically positioned flap technique with bone recontouring (resection) may be used to expose sound tooth structure. It can be done in case of fracture or caries. As a general rule, at least $4 \mathrm{~mm}$ of sound tooth structure must be exposed at time of will proliferate coronally to cover $2-3 \mathrm{~mm}$ of the root (Pontoriero \& Carnevale 2001), thereby leaving only $1-2 \mathrm{~mm}$ of supragingivally located sound tooth structure.(19)

- Indication: Crown lengthening of multiple teeth in a quadrant or sextant of the dentition.

- Contraindication: Surgical crown lengthening of single teeth in the esthetic zone.

\section{Forced tooth eruption}

Orthodontic tooth movement can be used to erupt teeth in adults. $(7,20,21)$ If moderate eruptive forces are used, the entire attachment apparatus will move in unison with the tooth. The tooth must be extruded a distance equal to or slightly longer than the portion of sound tooth structure that will be exposed in the subsequent surgical treatment. After the tooth has reached the intended position and has been stabilized, a full thickness flap bone recontouring is performed to expose sound root structure. For esthetic reasons it is important that the bone and soft tissue levels at adjacent teeth remain unchanged.

Forced tooth eruption can also be used to level and align gingival margins and the crowns of teeth to obtain esthetic harmony. Instead of using surgical procedures to apically position the gingival margins of unaffected normal teeth to the level of tooth with recession or orthodontic misalignment. The tooth that is malpositioned or has sustained recession is erupted to the level of the normally positioned teeth. The entire attachment apparatus and dentogingival junction will follow the root of the tooth as it is moved coronally.

- Indication: Crown lengthening at sites where removal of attachment and bone form adjacent teeth must be avoided. The forced eruption technique can also be used as means of reducing pocket depth at sites with angular bony defects.(7) The angular bony defect at the problem tooth can be reduced while the attachment level at the adjacent tooth surface remains unchanged.

- Contraindication: The forced eruption technique requires the use of fixed orthodontic appliances. Thus, in patients who have only a few teeth remaining, an alternative approach for crown lengthening has to be selected.

- Technique: Orthodontic brackets are bonded to the problem tooth and to adjacent teeth and are combined with an arch wire. Another type of mechanical system can be utilized by placing heavy gauge bar or wire in grooves prepared in the adjacent teeth and over the problem tooth. A power elastic is tied form the bracket to the arch wire (or the bar), which pulls to tooth coronally. If most of the crown structure is lost, root canal therapy is required. A post placed in the root canal is fitted with power elastic, which is also joined with the arch wire. The direction of the tooth movement must be carefully checked to ensure that the problem tooth is not tilted or moved toward the adjacent tooth surfaces.

\section{Forced tooth eruption with fibrotomy}

If fibrotomy is performed during the forced tooth eruption procedure the crestal bone and the gingival margin are retained at their pretreatment location and the tooth-gingiva interface at adjacent teeth is unaltered.(22) Fibrotomy is performed by the use of a scalpel at 7 to 10 day intervals during the forced eruption to sever the supracrestal connective tissue fibers, thereby preventing the crestal bone from following the root in coronal direction.

- Indication: Crown lengthening at sites where it is important to maintain unchanged the location of the gingival margin at adjacent teeth.

- Contraindication: Fibrotomy should not be used at teeth associated with angular bone defects, ectopically erupting tooth.

- Technique: Similar to the technique described for the forced tooth eruption procedure. Fibrotomy is performed once every 7-10 days during the phase of forced tooth eruption.

\section{Conclusion}

The health of the periodontal tissues is dependent on properly designed restorative materials. Overhanging restorations and open interproximal contacts should be addressed and remedied during the disease control phase of periodontal therapy. Regarding restorative margins can remain coronal to the free gingival margin. Obviously, subgingival margin placement is often unavoidable. However, care must be taken to involve as little of the sulcus as possible. Evidence suggests that even minimal encroachment on the subgingival tissue can lead to deleterious effects on the periodontium.

Furthermore, deep margin placement of the gingival to the tooth, often leading to a more pronounced plaque-induced inflammatory response. If restorative margins need to be placed near the alveolar crest, crown-lengthening surgery or orthodontic extrusion should be considered to provide adequate tooth structure while simultaneously assuring the integrity of the biologic width. Although individual variations exist in the soft tissue attachment around teeth there is general agreement that a minimum of $3 \mathrm{~mm}$ should exist from the restorative margin to the alveolar bone, allowing for $2 \mathrm{~mm}$ of biologic width space and $1 \mathrm{~mm}$ for sulcus depth. 


\section{THE AUTHORS}

\section{Dr. Nitin Khuller}

MDS

Senior Lecturer

Dept of Periodontics

ITS Dental College \& Hospital

Murad Nagar, Delhi- Meerut Road

Ghaziabad- 201206 (UP)

\section{Dr. Nikhil Sharma}

MDS

Senior Lecturer

Dept of Periodontics

ITS Dental College \& Hospital

Murad Nagar, Delhi- Meerut Road

Ghaziabad- 201206 (UP)

Email: nkhuller@yahoo.com

\section{References}

1. Garguilo AW, Wentz FM, Orban B. Mitotic activity of human oral epithelium exposed to 30 percent hydrogen peroxide. Oral Surg Oral Med Oral Path 1961;14:474-92.

2. Vacek JS, Gher ME, Assad DA, Richardson AC, Giambarresi LI. The dimensions of the human dentogingival junction. Int $J$ Periodontics Restorative Dent 1994;14(2):154-65.

3. Newcomb GM. The relationship between the location of subgingival crown margins and gingival inflammation. $J$ Periodontol1974;45(3):151-4.

4. Parma Benfenati S, Chiesa A, Rittà A, Di Fulvio W. Gingivoplasty. G Stomatol Ortognatodonzia 1986;5(4):57-8.

5. Tal $\mathrm{H}$, Soldinger $\mathrm{M}$, Dreiangel $\mathrm{A}$, Pitaru $\mathrm{S}$. Periodontal response to long-term abuse of the gingival attachment by supracrestal amalgam restorations. J Clin Periodontol 1989;16(10):654-9.

6. Gunay H, Seeger A, Tschernitschek H, Geurtsen W. Placement of Preperation Line and Periodontal Health- A Prospective 2 Year Clinical Study. Int J Perio Rest Dent 2000;20:173-81.

7. Ingber JS, Rose LF, Coslet JG. The "biologic width"-a concept in periodontics and restorative dentistry. Alpha Omegan 1977; 70(3):62-5.

8. Maynard JG Jr, Wilson RD. Physiologic dimensions of the periodontium significant to the restorative dentist. $J$ Periodontol 1979;50(4):170-4.

9. Nevins M, Skurow HM. The intracrevicular restorative margin, the biologic width, and the maintenance of the gingival margin. Int J Periodontics Restorative Dent 1984;4(3):30-49.

10. Leblebicioglu B, Rawal S, Mariotti A. A review of the functional and esthetic requirements for dental implants. J Am Dent Assoc Mar 2007; 138:321-29.

11. Orkin DA, Reddy J, Bradshaw D. The relationship of the position of crown margins to gingival health. J Prosthet Dent 1987;57(4):421-24.

12. Waerhaug J. Healing of the dento-epithelial junction following subgingival plaque control. II: As observed on extracted teeth. $J$ Periodontol 1978;49(3):119-34.

13. Stetler KJ, Bissada NF. Significance of the width of keratinized gingiva on the periodontal status of teeth with submarginal restorations. J Periodontol 1987;58(10):696-700.

14. Waerhaug J. Eruption of teeth into crowded position, loss of attachment, and downgrowth of subgingival plaque. Am J Orthod. 1980;78(4):453-9.

15. Dragoo MR, Williams GB. Periodontal tissue reactions to restorative procedures. Int J Periodontics Restorative Dent 1981; 1(1):8-23.

16. Flores-de-Jacoby L, Zafiropoulos GG, Ciancio S. Effect of crown margin location on plaque and periodontal health. Int $J$ Periodontics Restorative Dent 1989;9(3):197-205.

17. Newman MG, Takei HH, Klokkevold PR, Carranza FA. Clinical Periodontology, 10th Edition; Saunders-Elsevier, Missouri (USA).

18. Valderhaug J, Birkeland JM. Periodontal conditions in patients 5 years following insertion of fixed prostheses. Pocket depth and loss of attachment. J Oral Rehabil 1976;3(3):237-43.

19. Pontoriero R, Carnevale G. Surgical crown lengthening: a 12month clinical wound healing study. J Periodontol. 2001;72(7):8418.

20. Reitan K. Clinical and histologic observations on tooth movement during and after orthodontic treatment. Am $\mathrm{J}$ Orthod 1967;53(10):721-45.

21. Potashnick SR, Rosenberg ES. Forced eruption: principles in periodontics and restorative dentistry. J Prosthet Dent 1982; 48(2):141-8.

22. Felippe LA, Monteiro Junior S, Vierira LC, Araujo E. Reestablishing biologic width with forced eruption. Quintessence Int 2003;34: 733-738. 